\title{
Usefulness of Hematological Inflammatory Markers in Predicting Severe Side-effects from Induction Chemotherapy in Head and Neck Cancer Patients
}

\author{
TAKUYA MIKOSHIBA ${ }^{1}$, HIROYUKI OZAWA $^{1}$, SHIN SAITO $^{1}$, YUICHI IKARI ${ }^{1}$, \\ NANA NAKAHARA ${ }^{1}$, FUMIHIRO ITO $^{1}$, YOSHIHIRO WATANABE ${ }^{1,2}$, \\ MARIKO SEKIMIZU $^{1}$, YORIHISA IMANISHI ${ }^{1,3}$ and KAORU OGAWA \\ ${ }^{I}$ Department of Otolaryngology, Head and Neck Surgery, Keio University School of Medicine, Tokyo, Japan; \\ ${ }^{2}$ Department of Otorhinolaryngology, Head and Neck Surgery, Saiseikai Central Hospital, Tokyo, Japan; \\ ${ }^{3}$ Department of Otolaryngology, Head and Neck Surgery, Kawasaki Municipal Kawasaki Hospital, Kawasaki, Japan
}

\begin{abstract}
Background: Induction chemotherapy (IC) for head and neck cancer (HNC) often causes severe sideeffects. However, it has still been challenging to predict the adverse events. The present study aimed to evaluate the role of hematological inflammatory markers in predicting severe side-effects caused by IC. Materials and Methods: A total of 54 HNC patients who underwent IC were enrolled. The association between severe side-effects and pre-treatment hematological inflammatory markers [the $C$-reactive protein $(C R P)$ to albumin ratio (CAR), the modified Glasgow Prognostic Score ( $m G P S$ ), the neutrophil-to-lymphocyte ratio $(N L R)$, and the platelet-to-lymphocyte ratio $(P L R)]$ were evaluated. Results: In the univariate analysis, the incidence of whole severe side-effects (grade 4), febrile neutropenia (above grade 3), and hyponatremia (above grade 3) were significantly higher in the high CAR and high GPS groups. Multivariate analysis revealed that high CAR and $m G P S$ were independent predictors of these side-effects. Conclusion: CAR and mGPS were significant predictors of severe side-effects. These data can potentially offer patients an improved quality of life during cancer therapy.
\end{abstract}

For patients with head and neck squamous cell carcinoma (HNSCC), there are various complex treatment strategies. Combined modality therapy is generally recommended in

Correspondence to: Hiroyuki Ozawa, MD, Ph.D., Keio University School of Medicine, Otolaryngology, Head and Neck Surgery 35 Shinanomachi, Shinjuku-Ku, Tokyo 160-8582, Japan. Tel: +81 353633287, Fax: +81 333531261, e-mail: ozakky@cb.mbn.or.jp

Key Words: Hematological inflammatory markers, severe sideeffect, oropharyngeal and hypopharyngeal squamous cell carcinoma, TPF therapy, inflammatory cytokines. patients with locally- or regionally-advanced cases (1). The role of IC in HNSCC patients remains controversial. However, the rationale behind the concept of IC originally included several considerations, such as reducing distant metastasis, assessment of tumor responsiveness and altering subsequent therapy according to such responses, improved function through tumor shrinkage, and mucosal healing before further treatment (2). A combination of TPF ( $\mathrm{T}=$ docetaxel, $\mathrm{P}=$ cisplatin, and $\mathrm{F}=5$-fluorouracil) proved to be superior to that of PF in HNSCC (3-5), thus TPF chemotherapy is recommended as IC.

However, patients receiving systemic chemotherapy face the risk of suffering from severe side-effects. In particular, $76.9-84.6 \%, 5.2-23.1 \%$, and $23.1 \%$ of patients receiving TPF therapy had experienced grade 3 or 4 neutropenia, febrile neutropenia (FN), and hyponatremia, respectively, as sideeffects $(3,4,6)$. These complications cause the delay or discontinuation of subsequent therapy. Therefore, appropriate management of such side-effects is crucial as HNSCC patients often suffer from poor nutrition or inadequate organ functions. Although previous reports highlighted various risk factors of severe side-effects of chemotherapy such as pretreatment leukocyte counts, age, enteral nutrition and diabetes $(7,8)$, these data were limited to FN or bloodrelated toxicity, and further predictors of the severe sideeffects of TPF therapy are needed.

Recently, several hematological inflammatory markers that are considered to represent the patient's nutritional condition and/or immunologic status, including the Creactive protein (CRP) to albumin ratio (CAR), the modified Glasgow Prognostic Score (mGPS), the neutrophil to lymphocyte ratio (NLR), and the platelet to lymphocyte ratio (PLR), have been reported as possible prognostic predictors of various cancers (9-11) including head and neck cancers $(12,13)$. However, the predictive value of these markers for 
Table I. Patient characteristics.

\begin{tabular}{lc}
\hline Variables & Cases $(\mathrm{N}=54)$ \\
\hline Age & $66(46-86)$ \\
Median (range) & $52(96 \%) / 2(4 \%)$ \\
Gender & \\
Male/Female & $22.5(16.1-26.7)$ \\
BMI & $28(52 \%) / 26(48 \%)$ \\
Median (range) & \\
Site & $3(6 \%) / 28(52 \%) / 13(24 \%) / 10(19 \%)$ \\
OPC/HPC & \\
T classification & $10(19 \%) / 5(9 \%) / 38(70 \%) / 1(2 \%)$ \\
$1 / 2 / 3 / 4$ & \\
N classification & $1(2 \%) / 7(13 \%) / 5(9 \%) / 41(76 \%)$ \\
$0 / 1 / 2 / 3$ & $5(9 \%)$ \\
TNM Stage & $6(11 \%)$ \\
I/II/III/IV & $0(0 \%)$ \\
Co-morbidity & $0(0 \%)$ \\
Cardiocerebrovascular disease & $0(0 \%)$ \\
Diabetes & \\
Pulmonary disease & \\
Renal disease & \\
Tube feeding &
\end{tabular}

BMI, Body mass index; OPC, oropharyngeal carcinoma; HPC, hypopharyngeal carcinoma.

adverse events induced by chemotherapy has not been fully investigated. The purpose of this study was to evaluate the role of hematological inflammatory markers in predicting serious side-effects in HNSCC patients that have undergone TPF therapy as IC.

\section{Patients and Methods}

Patients. The medical chart of 57 oropharyngeal and hypopharyngeal squamous cell carcinoma (OHPSCC) patients who underwent the first cycle of TPF as IC and had never administered any chemotherapy at the Department of Otolaryngology, Head and Neck Surgery, Keio University School of Medicine from January 2012 to December 2015 were reviewed in this study. Three patients who did not have data for at least one of the following - CRP, albumin, neutrophil, lymphocyte, and platelets- before therapy were excluded. Finally, 54 patients were enrolled for this retrospective study, and their data, including BMI and Comorbidity status, were extracted from their medical records.

Treatment. Patients received both docetaxel $60 \mathrm{mg} / \mathrm{m}^{2}$ and cisplatin $60 \mathrm{mg} / \mathrm{m}^{2}$ on day 1 , and 5 -fluorouracil $700 \mathrm{mg} / \mathrm{m}^{2}$ from day 1 to day 4. A small number of patients received a reduced dose in consideration of their individual condition. Standard adjunct treatment of TPF therapy was administered. All patients were hospitalized for about 3 weeks, and were administered antiemetics (serotonin type 3 receptor antagonist, dexamethasone and neurokinin 1 receptor antagonist), hydrated around the cisplatin infusion with about 31 of $0.9 \%$ saline for renal protection, but not administered prophylactic antibiotics and G-CSF. Patients with either a decreased
Table II. Incidence of severe side-effects.

\begin{tabular}{|c|c|}
\hline Variables & Cases $(\mathrm{N}=54)$ \\
\hline \multicolumn{2}{|c|}{ Whole side-effects } \\
\hline Grade 3/4 & $34(63 \%) / 6(11 \%)$ \\
\hline \multicolumn{2}{|l|}{ Leucopenia } \\
\hline Grade 3/4 & $27(50 \%) / 3(6 \%)$ \\
\hline \multicolumn{2}{|l|}{ Neutropenia } \\
\hline Grade 3/4 & $22(41 \%) / 6(11 \%)$ \\
\hline \multicolumn{2}{|c|}{ Febrile neutropenia } \\
\hline Grade $3 / 4$ & $5(9 \%) / 0(0 \%)$ \\
\hline \multicolumn{2}{|l|}{ Anorexia } \\
\hline Grade $3 / 4$ & $17(31 \%) / 0(0 \%)$ \\
\hline \multicolumn{2}{|l|}{ Diarrhea } \\
\hline Grade 3/4 & $1(2 \%) / 0(0 \%)$ \\
\hline \multicolumn{2}{|c|}{ Nausea/Vomiting } \\
\hline Grade 3/4 & $1(2 \%) / 0(0 \%)$ \\
\hline \multicolumn{2}{|c|}{ Creatinine increased } \\
\hline Grade $3 / 4$ & $2(4 \%) / 0(0 \%)$ \\
\hline \multicolumn{2}{|c|}{ AST/ALT increased } \\
\hline Grade 3/4 & $1(2 \%) / 0(0 \%)$ \\
\hline \multicolumn{2}{|c|}{ Hyponatremia } \\
\hline Grade $3 / 4$ & $9(17 \%) / 0(0 \%)$ \\
\hline \multicolumn{2}{|c|}{ Lung infection } \\
\hline Grade 3/4 & $2(4 \%) / 0(0 \%)$ \\
\hline
\end{tabular}

WBC, White blood cell; AST, aspartate aminotransferase; ALT, alanine aminotransferase.

absolute neutrophil count under $500 / \mu 1$, or less than $1000 / \mu 1$ accompanied with high fever (FN) were given G-CSF injection.

Scoring systems. The CAR was defined as the serum CRP level divided by the serum albumin level. mGPS was estimated as described previously (14). Patients with a normal albumin ( $\geq 3.5 \mathrm{~g} / \mathrm{dl})$ and a normal CRP level $(<0.5 \mathrm{mg} / \mathrm{dl})$ were allocated a score of 0 , patients with both a low albumin level $(<3.5 \mathrm{~g} / \mathrm{dl})$ and an elevated CRP level $(\geq 0.5 \mathrm{mg} / \mathrm{dl})$ were allocated a score of 2 , while others were assigned a score of 1 . The NLR was defined as the absolute neutrophil count divided by the absolute lymphocyte count. The PLR was defined as the absolute platelet count divided by the absolute lymphocyte count. The receiver operator characteristic (ROC) analysis revealed the recommended cut-off value of CAR, NLR, and PLR as $0.15,2.72$, and 233.3, respectively. The value of each hematological inflammatory marker was calculated using pretreatment blood test results.

Data of side-effects counted in this study were applied from the completion of the first cycle of IC, and were graded according to the Common Terminology Criteria for Adverse Events v4.0 (CTCAE) classification. Those above grade 3 were defined as a severe side effect. Severe side-effects treated in this study were whole side-effects, leucopenia, neutropenia, FN, anorexia, diarrhea, nausea/vomiting, increase of creatinine, aspartate aminotransferase (AST), alanine aminotransferase (ALT), hyponatremia and lung infection. Whole side-effects (grade 4) showed that the cases experienced at least one side effect of grade 4 . We also evaluated the discontinuation or change in subsequent treatment, such as 
Mikoshiba et al: Hematological Inflammatory Markers in Predicting Side-effects

Table III. Univariate analysis of severe side-effects during induction chemotherapy stratified by the C-reactive protein (CRP) to albumin ratio $(C A R)$, the modified Glasgow Prognostic Score ( $m G P S)$, the neutrophil-to-lymphocyte ratio (NLR), and the platelet-to-lymphocyte ratio (PLR).

\begin{tabular}{|c|c|c|c|c|c|c|c|c|c|c|c|c|}
\hline & \multicolumn{3}{|c|}{ CAR } & \multicolumn{3}{|c|}{ mGPS } & \multicolumn{3}{|c|}{ NLR } & \multicolumn{3}{|c|}{ PLR } \\
\hline & $\begin{array}{l}<0.15 \\
(\mathrm{~N}=47)\end{array}$ & $\begin{array}{l}\geq 0.15 \\
(\mathrm{~N}=7)\end{array}$ & $p$-Value & $\begin{array}{c}0 \\
(\mathrm{~N}=46)\end{array}$ & $\begin{array}{c}1,2 \\
(\mathrm{~N}=8)\end{array}$ & $p$-Value & $\begin{array}{l}<2.72 \\
(\mathrm{~N}=26)\end{array}$ & $\begin{array}{l}\geq 2.72 \\
(\mathrm{~N}=28)\end{array}$ & $p$-Value & $\begin{array}{l}<233.3 \\
(\mathrm{~N}=47)\end{array}$ & $\begin{array}{r}\geq 233.3 \\
(\mathrm{~N}=7)\end{array}$ & $p$-Value \\
\hline $\begin{array}{l}\text { Whole side-effects } \\
\text { ( } \geq \text { Grade } 3 \text { ) }\end{array}$ & $34(72 \%)$ & $6(86 \%)$ & 0.409 & $34(74 \%)$ & $6(75 \%)$ & 0.66 & $19(73 \%)$ & $21(75 \%)$ & 0.872 & $35(75 \%)$ & $5(71 \%)$ & 0.591 \\
\hline $\begin{array}{l}\text { Whole side-effects } \\
\text { ( } \geq \text { Grade } 4)\end{array}$ & $3(6 \%)$ & $3(43 \%)$ & 0.023 & $3(7 \%)$ & $3(38 \%)$ & 0.036 & $2(8 \%)$ & $4(14 \%)$ & 0.371 & $5(11 \%)$ & $1(14 \%)$ & 0.584 \\
\hline $\begin{array}{l}\text { Leucopenia } \\
\qquad(\geq \text { Grade } 3)\end{array}$ & $26(55 \%)$ & $4(57 \%)$ & 0.627 & $26(57 \%)$ & $4(50 \%)$ & 0.51 & $14(54 \%)$ & $16(57 \%)$ & 0.808 & $25(53 \%)$ & $5(71 \%)$ & 0.314 \\
\hline $\begin{array}{r}\text { Neutropenia } \\
(\geq \text { Grade } 3)\end{array}$ & $24(51 \%)$ & $4(57 \%)$ & 0.543 & $24(52 \%)$ & $4(50 \%)$ & 0.6 & $12(46 \%)$ & $16(57 \%)$ & 0.419 & $23(49 \%)$ & $5(71 \%)$ & 0.242 \\
\hline $\begin{array}{l}\text { Febrile neutropenia } \\
\text { ( } \geq \text { Grade } 3)\end{array}$ & $2(4 \%)$ & $3(43 \%)$ & 0.012 & $2(4 \%)$ & $3(38 \%)$ & 0.019 & $1(4 \%)$ & $4(14 \%)$ & 0.199 & $4(9 \%)$ & $1(14 \%)$ & 0.515 \\
\hline $\begin{array}{l}\text { Anorexia } \\
(\geq \text { Grade } 3)\end{array}$ & $11(23 \%)$ & $6(86 \%)$ & 0.003 & $11(24 \%)$ & $6(75 \%)$ & 0.009 & $6(23 \%)$ & $11(39 \%)$ & 0.2 & $13(28 \%)$ & $4(57 \%)$ & 0.13 \\
\hline $\begin{array}{l}\text { Diarrhea } \\
\qquad(\geq \text { Grade } 3)\end{array}$ & $0(0 \%)$ & $1(14 \%)$ & 0.13 & $0(0 \%)$ & $1(13 \%)$ & 0.148 & $0(0 \%)$ & $1(4 \%)$ & 0.519 & $1(2 \%)$ & $0(0 \%)$ & 0.87 \\
\hline $\begin{array}{l}\text { Nausea/Vomiting } \\
\text { ( } \geq \text { Grade } 3)\end{array}$ & $0(0 \%)$ & $1(14 \%)$ & 0.148 & $0(0 \%)$ & $1(13 \%)$ & 0.148 & $0(0 \%)$ & $1(4 \%)$ & 0.519 & $1(2 \%)$ & $0(0 \%)$ & 0.87 \\
\hline $\begin{array}{l}\text { Creatinine increased } \\
(\geq \text { Grade } 3)\end{array}$ & $1(2 \%)$ & $1(14 \%)$ & 0.245 & $1(2 \%)$ & $1(13 \%)$ & 0.277 & $0(0 \%)$ & $2(7 \%)$ & 0.264 & $2(4 \%)$ & $0(0 \%)$ & 0.755 \\
\hline $\begin{array}{l}\text { AST/ALT increased } \\
(\geq \text { Grade } 3)\end{array}$ & $1(2 \%)$ & $0(0 \%)$ & 0.87 & $1(2 \%)$ & $0(0 \%)$ & 0.852 & $0(0 \%)$ & $1(4 \%)$ & 0.519 & $1(2 \%)$ & $0(0 \%)$ & 0.87 \\
\hline $\begin{array}{l}\text { Hyponatremia } \\
\text { ( } \geq \text { Grade } 3 \text { ) }\end{array}$ & $5(11 \%)$ & $4(57 \%)$ & 0.011 & $5(11 \%)$ & $4(50 \%)$ & 0.02 & $3(12 \%)$ & $6(21 \%)$ & 0.273 & $8(17 \%)$ & $1(14 \%)$ & 0.67 \\
\hline $\begin{array}{l}\text { Lung infection } \\
\text { ( } \geq \text { Grade } 3 \text { ) }\end{array}$ & $2(4 \%)$ & $0(0 \%)$ & 0.755 & $2(4 \%)$ & $0(0 \%)$ & 0.723 & $0(0 \%)$ & $2(7 \%)$ & 0.264 & $1(2 \%)$ & $1(14 \%)$ & 0.245 \\
\hline $\begin{array}{l}\text { Discontinuation or } \\
\text { change the treatment }\end{array}$ & $5(11 \%)$ & $2(29 \%)$ & 0.22 & $5(11 \%)$ & $2(25 \%)$ & 0.275 & $2(8 \%)$ & $5(18 \%)$ & 0.242 & $6(13 \%)$ & $1(14 \%)$ & 0.645 \\
\hline
\end{tabular}

reducing the amount of drug, or altering the regimen according to the patient's condition resulting from the side-effects of IC.

Statistical analysis. On univariate analysis, associations between categorical variables were assessed using the chi-square test or Fisher's exact test. Associations between continuous variables were assessed using the $t$-test or Mann Whitney test. Multivariate analysis was performed using a multivariate logistic regression model with the backward elimination method. All data were analyzed using SPSS v23 for Mac (IBM Chicago, IL, USA). A $p$-value of $<0.05$ was considered statistically significant.

The Institutional Review Board and Research Ethics Committee approved the study (reference number: 20100013). The requirement for informed consent was waived owing to the retrospective nature of the analysis.

\section{Results}

Tables I and II show the patient characteristics and the incidence of severe side-effects evaluated in the study. The mean age of the patients was 66 years, with a range of 46 to 86 years. A total of 52 were males. There were 28 with oropharyngeal carcinoma and 26 with hypopharyngeal carcinoma. Forty-six patients were at an advanced stage (III-IV), 23 patients had locally advanced $(\mathrm{T} 3,4)$, and 44 patients had cervical lymph node metastasis. There were no deaths associated with IC.

Univariate analysis revealed that the incidence of whole severe side-effects (grade 4), FN, anorexia, and hyponatremia (above grade 3) were significantly higher in patients in the high CAR and high mGPS groups. On the other hand, NLR and PLR had no significant correlation with any side-effects (Table III). None of these markers were detected as significant predictors of discontinuation or change of subsequent treatment. We examined the other clinical factors associated with whole severe side-effects (grade 4), FN, anorexia, and hyponatremia (above grade 3) (Table IV). For whole severe side-effects (grade 4), FN and hyponatremia (above grade 3 ), none of the clinical factors except mGPS and CAR were significant associations including pretreatment CRP or albumin alone. For anorexia (above grade 3 ), stage, $\mathrm{T}$ stage and $\mathrm{N}$ stage were also significantly associated. 
Table IV. Univariate analysis of factors predicting the severe side-effects during induction chemotherapy.

\begin{tabular}{|c|c|c|c|c|c|c|c|c|c|c|c|c|}
\hline & \multicolumn{3}{|c|}{$\begin{array}{l}\text { Whole side-effects } \\
\text { (grade 4) }\end{array}$} & \multicolumn{3}{|c|}{$\begin{array}{l}\text { Febrile neutropenia } \\
\quad(\geq \text { grade } 3)\end{array}$} & \multicolumn{3}{|c|}{$\begin{array}{l}\text { Hyponatremia } \\
\text { ( } \geq \text { grade 3) }\end{array}$} & \multicolumn{3}{|c|}{$\begin{array}{l}\text { Anorexia } \\
(\geq \text { grade 3) }\end{array}$} \\
\hline & Yes & No & $p$-Value & Yes & No & $p$-Value & Yes & No & $p$-Value & Yes & No & $p$-Value \\
\hline CAR $(\geq 0.15)$ & $3 / 3$ & $4 / 44$ & 0.023 & $3 / 2$ & $4 / 45$ & 0.012 & $4 / 5$ & $3 / 42$ & 0.011 & $6 / 11$ & $1 / 36$ & 0.003 \\
\hline mGPS & $3 / 3$ & $5 / 43$ & 0.036 & $3 / 2$ & $5 / 44$ & 0.019 & $4 / 5$ & $4 / 41$ & 0.020 & $6 / 11$ & $2 / 35$ & 0.009 \\
\hline Age & 71.3 & 65.8 & 0.119 & 66.2 & 66.5 & 0.945 & 71.9 & 65.4 & 0.086 & 66.4 & 66.4 & 0.987 \\
\hline Gender (male/female) & $0 / 6$ & $2 / 46$ & 0.788 & $5 / 0$ & $47 / 2$ & 0.822 & $9 / 0$ & $43 / 2$ & 0.692 & $16 / 1$ & $36 / 1$ & 0.535 \\
\hline BMI & 22.2 & 22.6 & 0.763 & 23.3 & 22.5 & 0.479 & 22.0 & 22.6 & 0.524 & 21.8 & 22.9 & 0.167 \\
\hline Site (OPC/HPC) & $1 / 5$ & $27 / 21$ & 0.080 & $1 / 4$ & $27 / 22$ & 0.153 & $5 / 4$ & $23 / 22$ & 0.549 & $11 / 6$ & $17 / 20$ & 0.162 \\
\hline TNM Stage (III-IV/I-II) & $4 / 2$ & $42 / 6$ & 0.213 & $5 / 0$ & $41 / 8$ & 0.433 & $9 / 0$ & $37 / 8$ & 0.207 & $17 / 0$ & $29 / 8$ & 0.037 \\
\hline $\mathrm{T}$ classification $(3-4 / 1-2)$ & $3 / 3$ & $20 / 28$ & 0.512 & $4 / 1$ & $19 / 30$ & 0.097 & $5 / 4$ & $18 / 27$ & 0.309 & $11 / 6$ & $12 / 25$ & 0.027 \\
\hline $\mathrm{N}$ classification $(1-3 / 0)$ & $4 / 2$ & $40 / 8$ & 0.306 & $5 / 0$ & $39 / 10$ & 0.343 & $9 / 0$ & $35 / 10$ & 0.133 & $17 / 0$ & $27 / 10$ & 0.015 \\
\hline $\begin{array}{l}\text { Pre-treatment WBC } \\
\text { (abnormal/normal)* }\end{array}$ & $0 / 6$ & $6 / 42$ & 0.475 & $1 / 4$ & $5 / 44$ & 0.459 & $1 / 8$ & $5 / 40$ & 0.741 & $2 / 15$ & $4 / 33$ & 0.623 \\
\hline $\begin{array}{l}\text { Pre-treatment Neu } \\
\text { (abnormal/normal)* }\end{array}$ & $0 / 6$ & $9 / 39$ & 0.315 & $1 / 4$ & $8 / 41$ & 0.614 & $3 / 6$ & $6 / 39$ & 0.161 & $4 / 13$ & $5 / 32$ & 0.293 \\
\hline $\begin{array}{l}\text { Pre-treatment Mono } \\
\text { (abnormal/normal)* }\end{array}$ & $0 / 6$ & $4 / 44$ & 0.615 & $1 / 4$ & $3 / 46$ & 0.330 & $2 / 7$ & $2 / 43$ & 0.125 & $2 / 15$ & $2 / 35$ & 0.373 \\
\hline $\begin{array}{l}\text { Pre-treatment Plt } \\
\text { (abnormal/normal)* }\end{array}$ & $0 / 6$ & $3 / 43$ & 0.687 & $0 / 5$ & $3 / 46$ & 0.743 & $1 / 8$ & $2 / 43$ & 0.428 & $1 / 16$ & $2 / 33$ & 0.704 \\
\hline $\begin{array}{l}\text { Pre-treatment Alb } \\
(\geq 3.5 /<3.5 \mathrm{~g} / \mathrm{dl})\end{array}$ & $1 / 5$ & $1 / 47$ & 0.212 & $0 / 5$ & $2 / 47$ & 0.822 & $1 / 8$ & $1 / 44$ & 0.308 & $2 / 15$ & $0 / 37$ & 0.095 \\
\hline $\begin{array}{l}\text { Pre-treatment CRP } \\
(\geq 0.3 /<0.3 \mathrm{mg} / \mathrm{dl})\end{array}$ & $3 / 3$ & $8 / 40$ & 0.091 & $3 / 2$ & $8 / 41$ & 0.052 & $4 / 5$ & $7 / 38$ & 0.072 & $6 / 11$ & $5 / 32$ & 0.072 \\
\hline $\begin{array}{l}\text { Pre-treatment } \mathrm{Na} \\
(135>/ \geq 135) \\
\text { Co-morbidity }\end{array}$ & $0 / 6$ & $1 / 47$ & 0.889 & $0 / 5$ & $1 / 48$ & 0.907 & $0 / 9$ & $1 / 44$ & 0.833 & $0 / 17$ & $1 / 36$ & 0.685 \\
\hline Cardiocerebrovascular disease & $2 / 4$ & $3 / 45$ & 0.089 & $1 / 4$ & $4 / 45$ & 0.397 & $1 / 8$ & $4 / 41$ & 0.614 & $1 / 16$ & $4 / 33$ & 0.493 \\
\hline Diabetes & $0 / 6$ & $6 / 42$ & 0.475 & $0 / 5$ & $6 / 43$ & 0.541 & $2 / 7$ & $4 / 41$ & 0.259 & $1 / 16$ & $5 / 32$ & 0.377 \\
\hline
\end{tabular}

Neu, Neutrophil; Mono, monocyte; Plt, platelet; Alb, albumin; CRP, C-reactive protein; Na, natrium.*According to our institutional standard, normal

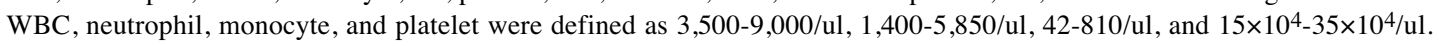

We focused on whole severe side-effects (grade 4), FN (above grade 3), and hyponatremia (above grade 3) for multivariate analysis. Whole severe side-effects (grade 4) were more frequent in the high CAR group (odds ratio $(\mathrm{OR})=12.5$, $95 \%$ confidence interval $(\mathrm{CI})=1.582-100.641, p=0.017)$ and the high mGPS group (OR=10.1, 95\%CI=1.331-76.694, $p=0.025)$. FN (above grade 3 ) was more frequent in the high CAR group $(\mathrm{OR}=16.9,95 \% \mathrm{CI}=2.149-132.508, p=0.007)$ and the high mGPS group (OR=13.2, 95\% CI=1.761-98.926, $p=0.012$ ). Hyponatremia (above grade 3 ) was more frequent in the high CAR group (OR=11.2, 95\% CI=1.925-65.155, $p=0.007)$ and the high mGPS group (OR=8.2, 95\% CI=1.546-43.479, $p=0.018$ ) (Table V). High CAR and mGPS were independent predictors of these side-effects.

\section{Discussion}

The results of this study indicate that CAR and mGPS can be useful predictors of the severe side-effects in OHPSCC patients receiving TPF therapy. To the best of our knowledge, only two reports have described the predictive role of inflammatory markers or nutritional factors in severe complications with chemotherapy $(15,16)$. Kono et al. reported Onodera's prognostic nutrition index as a useful nutritional factor for predicting severe side-effects in HNSCC patients receiving chemoradiotherapy (15). Tominaga et al. demonstrated that CAR was a novel, promising inflammation-based score for above grade 3 sideeffects of adjuvant chemotherapy for colorectal cancers (16). The present study represents the first report on the predictive value of hematological inflammatory markers, especially with regard to the severe side-effects in HNSCC patients treated with TPF therapy, which is universally recommended as an IC. Evaluating CAR and mGPS is straightforward in routine checks before chemotherapy and is inexpensive. While CAR is calculated as serum CRP level/serum albumin level and has an optimal cut-off value, mGPS is evaluated as a score. Both of these two markers can be used depending 
Table V. Multivariate analysis of occurrence of severe side-effects.

\begin{tabular}{|c|c|c|c|c|c|c|c|c|c|}
\hline & \multicolumn{3}{|c|}{ Whole side-effects (grade 4) } & \multicolumn{3}{|c|}{ Febrile neutropenia ( $\geq$ grade 3 ) } & \multicolumn{3}{|c|}{ Hyponatremia ( $\geq$ grade 3 ) } \\
\hline & OR & $95 \% \mathrm{CI}$ & $p$-Value & OR & $95 \% \mathrm{CI}$ & $p$-Value & OR & $95 \% \mathrm{CI}$ & $p$-Value \\
\hline CAR $(\geq 0.15)$ & 12.6 & $1.582-100.641$ & 0.017 & 16.9 & $2.149-132.508$ & 0.007 & 11.2 & $1.925-65.155$ & 0.007 \\
\hline mGPS & 10.1 & $1.331-76.694$ & 0.025 & 13.2 & $1.761-98.926$ & 0.012 & 8.2 & $1.546-43.479$ & 0.013 \\
\hline
\end{tabular}

on the clinical situation. In patients with high CAR or mGPS prior to IC, it should be carefully considered whether IC is beneficial or harmful. We should also start preceding treatment for side-effects, which can help patients with a better quality of life during cancer therapy.

As both CAR and mGPS were predictors of the severe side-effects of TPF therapy, high serum CRP plays an essential role in the side-effects of chemotherapeutic reagents. CRP elevation is often observed in patients with advanced cancer, mostly due to the high levels of cytokines and chemokines, such as IL-6, IL-8, and TNF-alpha secreted from cancer cells or surrounding organs (17). Several studies have reported that elevated cytokine and CRP can induce cancer-related symptoms, including neutropenia, fatigue, pain, and cachexia (18-20). Moreover, chemotherapeutic reagents themselves also trigger cytokine secretion from cancer cells $(21,22)$. The elevation of serum cytokines is a risk factor for serious side-effects during chemotherapy (23). Although CRP elevation can be caused by other factors such as infections or co-existing diseases, we should pay attention to pre-treatment CRP levels that might reflect an extent of serum cytokine elevation that could cause intolerance to chemotherapy.

Pre-treatment CAR and mGPS were reliable predictors for hyponatremia in this study, suggesting that chemotherapyinduced hyponatremia may also be associated with inflammatory cytokines, which is consistent with previous reports (24). Elevated levels of inflammatory cytokines such as IL-1 $\beta$ or IL- 6 were indicated to promote antidiuretic hormone $(\mathrm{ADH})$ secretion resulting in hyponatremia known as the syndrome of inappropriate ADH (SIADH) (24). Since high CAR and mGPS has the possibility to be associated with elevated cytokine levels as mentioned above, OHPSCC patients with high pre-treatment CAR and mGPS might be vulnerable to SIADH influenced by TPF therapy, although other causes of hyponatremia such as intake deficiency, vomiting, and the effect of drugs may also contribute to SIADH.

NLR and PLR were insufficient as predictors of the severe side-effects in our study, although both NLR and PLR have been reported as being effective markers with regard to tumor prognosis in various cancers $(10,25,26)$. The superiority of CAR and mGPS to NLR and PLR as predictors of side-effects has been previously reported (16) in accordance with our results, although such superiority among various markers may rather depend on the variation of cancer types and/or chemotherapy regimens between studies. While NLR and PLR may reflect the balance between tumor-promoting inflammation and host immunity (27), CAR and mGPS are assumed to reflect the balance between cytokines-induced inflammation and nutrition status. Accordingly, our results suggest that inflammatory cytokines associated with CRP elevation and impaired nutrition status might be more closely involved in the development of the side-effects of IC, compared to the immune status affected by imbalance in the hematological cellular components.

There were several limitations in this study. First, there may be inevitable bias in a retrospective study. The sample size was small and from a single institution and TPF regimen in this study had a small modification from the standard dose, which may affect the results. We were unable to completely eliminate other factors that affect inflammatory markers such as infection, autoimmune disease and so on. In the future, larger prospective studies are needed to strengthen the results of this study.

\section{Conclusion}

The present study showed that the hematological inflammatory markers (CAR/mGPS) are a significant predictor of the severe side-effects of OHPSCC receiving TPF therapy. In particular, pre-treatment CAR and mGPS can be predictive markers for grade 4 side-effects, FN, and hyponatremia.

\section{Conflicts of Interest}

The Authors have no conflicts of interest to declare.

\section{Authors' Contributions}

All listed Authors substantially contributed to the following aspects of the manuscript: TM, HO, SS, YI, NN, FI, YW, and MS participated in patient diagnosis and treatment and in data acquisition. TM, HO, and YI collected the findings and drafted the 
manuscript. HO, YI, and KO revised the manuscript. All Authors read and approved the final manuscript.

\section{References}

1 NCCN Guideline: Head and neck cancers, 2017. Available at: https://www.ncen.org/

2 Busch CJ, Tribius S, Schafhausen P and Knecht R: The current role of systemic chemotherapy in the primary treatment of head and neck cancer. Cancer Treat Rev 41(3): 217-221, 2015. PMID: 25687982. DOI: $10.1016 /$ j.ctrv.2015.02.002

3 Vermorken JB, Remenar E, van Herpen C, Gorlia T, Mesia R, Degardin M, Stewart JS, Jelic S, Betka J, Preiss JH, van den Weyngaert D, Awada A, Cupissol D, Kienzer HR, Rey A, Desaunois I, Bernier J and Lefebvre JL: Cisplatin, fluorouracil, and docetaxel in unresectable head and neck cancer. N Engl J Med 357(17): 1695-1704, 2007. PMID: 17960012. DOI: 10.1056/NEJMoa071028

4 Posner MR, Hershock DM, Blajman CR, Mickiewicz E, Winquist E, Gorbounova V, Tjulandin S, Shin DM, Cullen K, Ervin TJ, Murphy BA, Raez LE, Cohen RB, Spaulding M, Tishler RB, Roth B, Viroglio Rdel C, Venkatesan V, Romanov I, Agarwala S, Harter KW, Dugan M, Cmelak A, Markoe AM, Read PW, Steinbrenner L, Colevas AD, Norris CM Jr. and Haddad RI: Cisplatin and fluorouracil alone or with docetaxel in head and neck cancer. N Engl J Med 357(17): 1705-1715, 2007. PMID: 17960013. DOI: 10.1056/NEJMoa070956

5 Pointreau Y, Garaud P, Chapet S, Sire C, Tuchais C, Tortochaux J, Faivre S, Guerrif S, Alfonsi M and Calais G: Randomized trial of induction chemotherapy with cisplatin and 5-fluorouracil with or without docetaxel for larynx preservation. J Natl Cancer Inst 101(7): 498-506, 2009. PMID: 19318632. DOI: 10.1093/jnci/ djp007

6 Izawa N, Onozawa Y, Hikosaka T, Hamauchi S, Tsushima T, Todaka A, Machida N, Haraguchi Y, Ogawa H, Nishimura T, Nakagawa M, Fuke T, Iida Y, Kamijo T, Onitsuka T, Boku N, Yasui $\mathrm{H}$ and Yokota T: Efficacy and feasibility of docetaxel, cisplatin, and 5-fluorouracil induction chemotherapy for locally advanced head and neck squamous cell carcinoma classified as clinical nodal stage $\mathrm{n} 2 \mathrm{c}, \mathrm{n} 3$, or $\mathrm{n} 2 \mathrm{~b}$ with supraclavicular lymph node metastases. Int J Clin Oncol 20(3): 455-462, 2015. PMID: 25248339. DOI: $10.1007 / \mathrm{s} 10147-014-0749-4$

7 Aapro MS, Bohlius J, Cameron DA, Dal Lago L, Donnelly JP, Kearney N, Lyman GH, Pettengell R, Tjan-Heijnen VC, Walewski J, Weber DC and Zielinski C: 2010 update of eortc guidelines for the use of granulocyte-colony stimulating factor to reduce the incidence of chemotherapy-induced febrile neutropenia in adult patients with lymphoproliferative disorders and solid tumours. Eur J Cancer 47(1): 8-32, 2011. PMID: 21095116. DOI: 10.1016/j.ejca.2010.10.013

8 Takenaka Y, Cho H, Yamamoto M, Nakahara S, Yamamoto Y and Inohara $\mathrm{H}$ : Incidence and predictors of febrile neutropenia during chemotherapy in patients with head and neck cancer. Support Care Cancer 21(10): 2861-2868, 2013. PMID: 23748486. DOI: $10.1007 / \mathrm{s} 00520-013-1873-9$

9 Kinoshita A, Onoda H, Imai N, Iwaku A, Oishi M, Tanaka K, Fushiya N, Koike K, Nishino H, Matsushima M, Saeki C and Tajiri H: The glasgow prognostic score, an inflammation based prognostic score, predicts survival in patients with hepatocellular carcinoma. BMC Cancer 13: 52, 2013. PMID: 23374755. DOI: 10.1186/1471-2407-13-52
10 Wang DS, Luo HY, Qiu MZ, Wang ZQ, Zhang DS, Wang FH, $\mathrm{Li} \mathrm{YH}$ and $\mathrm{Xu} \mathrm{RH}$ : Comparison of the prognostic values of various inflammation based factors in patients with pancreatic cancer. Med Oncol 29(5): 3092-3100, 2012. PMID: 22476808. DOI: $10.1007 / \mathrm{s} 12032-012-0226-8$

11 Wang DS, Ren C, Qiu MZ, Luo HY, Wang ZQ, Zhang DS, Wang FH, Li YH and Xu RH: Comparison of the prognostic value of various preoperative inflammation-based factors in patients with stage iii gastric cancer. Tumour Biol 33(3): 749756, 2012. PMID: 22198641. DOI: 10.1007/s13277-0110285-z

12 Kawakita D, Tada Y, Imanishi Y, Beppu S, Tsukahara K, Kano S, Ozawa H, Okami K, Sato Y, Shimizu A, Sato Y, Fushimi C, Takase S, Okada T, Sato H, Otsuka K, Watanabe Y, Sakai A, Ebisumoto K, Togashi T, Ueki Y, Ota H, Shimura T, Hanazawa $\mathrm{T}$, Murakami $\mathrm{S}$ and Nagao $\mathrm{T}$ : Impact of hematological inflammatory markers on clinical outcome in patients with salivary duct carcinoma: A multi-institutional study in japan. Oncotarget 8(1): 1083-1091, 2017. PMID: 27894101. DOI: 10.18632 /oncotarget. 13565

13 Nakayama M, Tabuchi K and Hara A: Clinical utility of the modified glasgow prognostic score in patients with advanced head and neck cancer. Head Neck 37(12): 1745-1749, 2015. PMID: 24989115. DOI: 10.1002/hed 23823

14 Toiyama Y, Miki C, Inoue Y, Tanaka K, Mohri Y and Kusunoki M: Evaluation of an inflammation-based prognostic score for the identification of patients requiring postoperative adjuvant chemotherapy for stage ii colorectal cancer. Exp Ther Med 2(1): 95-101, 2011. PMID: 22977476. DOI: 10.3892/etm.2010.175

15 Kono T, Sakamoto K, Shinden S and Ogawa K: Pre-therapeutic nutritional assessment for predicting severe adverse events in patients with head and neck cancer treated by radiotherapy. Clin Nutr 36(6): 1681-1685, 2016. PMID: 27847115. DOI: 10.1016/j.clnu.2016.10.021

16 Tominaga T, Nonaka T, Sumida Y, Hidaka S, Sawai T and Nagayasu T: The c-reactive protein to albumin ratio as a predictor of severe side-effects of adjuvant chemotherapy in stage iii colorectal cancer patients. PLoS One 11(12): e0167967, 2016. PMID: 27930703. DOI: 10.1371/journal.pone.0167967

17 Allin KH, Bojesen SE and Nordestgaard BG: Baseline c-reactive protein is associated with incident cancer and survival in patients with cancer. J Clin Oncol 27(13): 2217-2224, 2009. PMID: 19289618. DOI: $10.1200 /$ JCO.2008.19.8440

18 Paulsen O, Laird B, Aass N, Lea T, Fayers P, Kaasa S and Klepstad P: The relationship between pro-inflammatory cytokines and pain, appetite and fatigue in patients with advanced cancer. PLoS One 12(5): e0177620, 2017. PMID: 28542626. DOI: 10.1371/journal.pone.0177620

19 Cleeland CS, Bennett GJ, Dantzer R, Dougherty PM, Dunn AJ, Meyers CA, Miller AH, Payne R, Reuben JM, Wang XS and Lee $\mathrm{BN}$ : Are the symptoms of cancer and cancer treatment due to a shared biologic mechanism? A cytokine-immunologic model of cancer symptoms. Cancer 97(11): 2919-2925, 2003. PMID: 12767108. DOI: $10.1002 /$ cncr.11382

20 Srdic D, Plestina S, Sverko-Peternac A, Nikolac N, Simundic AM and Samarzija M: Cancer cachexia, sarcopenia and biochemical markers in patients with advanced non-small cell lung cancer-chemotherapy toxicity and prognostic value. Support Care Cancer 24(11): 4495-4502, 2016. PMID: 27236439. DOI: $10.1007 / \mathrm{s} 00520-016-3287-\mathrm{y}$ 
21 Suzuki T, Takeuchi M, Saeki H, Yamazaki S, Koga H, Abe D, Nishimura M, Nakaseko C, Nakasa H, Nakamura H, Ariyoshi N and Kitada M: Super-acute onset of tumor lysis syndrome accompanied by hypercytokinemia during treatment of hodgkin's lymphoma with abvd chemotherapy. Clin Ther 32(3): 527-531, 2010. PMID: 20399989. DOI: 10.1016/j.clinthera.2010.03.010

22 Nakamura M, Oda S, Sadahiro T, Hirayama Y, Tateishi Y, Abe $\mathrm{R}$ and Hirasawa $\mathrm{H}$ : The role of hypercytokinemia in the pathophysiology of tumor lysis syndrome (tls) and the treatment with continuous hemodiafiltration using a polymethylmethacrylate membrane hemofilter (pmma-chdf). Transfus Apher Sci 40(1): 41-47, 2009. PMID: 19109071. DOI: 10.1016/j.transci. 2008.11.004

23 Tromp YH, Daenen SM, Sluiter WJ and Vellenga E: The predictive value of interleukin-8 (il-8) in hospitalised patients with fever and chemotherapy-induced neutropenia. Eur J Cancer 45(4): 596-600, 2009. PMID:19095436. DOI: 10.1016/j.ejca. 2008.10.041

24 Park SJ and Shin JI: Inflammation and hyponatremia: An underrecognized condition? Korean J Pediatr 56(12): 519-522, 2013. PMID: 24416046. DOI: 10.3345/kjp.2013.56.12.519
25 Wang PF, Song HW, Cai HQ, Kong LW, Yao K, Jiang T, Li SW and Yan CX: Preoperative inflammation markers and idh mutation status predict glioblastoma patient survival. Oncotarget 8(30): 50117-50123, 2017. PMID: 28223536. DOI: 10.18632/ oncotarget.15235

26 Paramanathan A, Saxena A and Morris DL: A systematic review and meta-analysis on the impact of pre-operative neutrophil lymphocyte ratio on long term outcomes after curative intent resection of solid tumours. Surg Oncol 23(1): 31-39, 2014. PMID: 24378193. DOI: 10.1016/j.suronc.2013.12.001

27 Zheng RR, Huang M, Jin C, Wang HC, Yu JT, Zeng LC, Zheng FY and Lin F: Cervical cancer systemic inflammation score: A novel predictor of prognosis. Oncotarget 7(12): 15230-15242, 2016. PMID: 26885692. DOI: $10.18632 /$ oncotarget.7378

Received April 9, 2019

Revised May 18, 2019

Accepted May 20, 2019 